\title{
Animal-Assisted and Pet-Robot Interventions for Ameliorating Behavioral and Psychological Symptoms of Dementia: A Systematic Review and Meta-Analysis
}

\author{
Sangki Park ${ }^{1,+}$, Ahream Bak ${ }^{2,+}$, Sujin Kim ${ }^{3,+}$, Yunkwon Nam ${ }^{3}$, Hyeon soo Kim ${ }^{3}$ (D, \\ Doo-Han Yoo ${ }^{1, *}$ and Minho Moon ${ }^{3, *}$ \\ 1 Department of Occupational Therapy, Konyang University, 158, Gwanjeodong-ro, Seo-gu, Daejeon \\ 35365, Korea; sangki0222@gmail.com \\ 2 Department of Occupational Therapy, Jeonju Kijeon College, 267, Jeonjucheonseo-ro, Wansan-gu, \\ Junju 54989, Korea; orang43@naver.com \\ 3 Department of Biochemistry, College of Medicine, Konyang University, 158, Gwanjeodong-ro, Seo-gu, \\ Daejeon 35365, Korea; aktnfl3371@naver.com (S.K.); yunkwonnam@gmail.com (Y.N.); \\ sooya1105@naver.com (H.s.K) \\ * Correspondence: glovia@konyang.ac.kr (D.-H.Y.); hominmoon@konyang.ac.kr (M.M.); \\ Tel.: +82-42-600-8414 (D.-H.Y.); +82-42-600-8691 (M.M.) \\ + These authors contributed equally to this work.
}

Received: 11 May 2020; Accepted: 1 June 2020; Published: 2 June 2020

\begin{abstract}
Patients with dementia suffer from psychological symptoms such as depression, agitation, and aggression. One purpose of dementia intervention is to manage patients' inappropriate behaviors and psychological symptoms while taking into consideration their quality of life (QOL). Animal-assisted intervention (AAI) and pet-robot intervention (PRI) are effective intervention strategies for older people with cognitive impairment and dementia. In addition, AAI and PRI have been shown to have positive effects on behavioral and psychological symptoms of dementia (BPSD). However, studies into the association between AAI/PRI and BPSD have elicited inconsistent results. Thus, we performed a meta-analysis to investigate this association. We analyzed nine randomized controlled trials on AAI and PRI for dementia patients published between January 2000 and August 2019 and evaluated the impact of AAI/PRI on agitation, depression, and QOL. We found that AAI and PRI significantly reduce depression in patients with dementia. Subsequent studies should investigate the impact of AAI and PRI on the physical ability and cognitive function of dementia patients and conduct a follow-up to investigate their effects on the rate of progression and reduction of symptoms of dementia. Our research will help with neuropsychological and environmental intervention to delay or improve the development and progression of BPSD.
\end{abstract}

Keywords: dementia; behavioral and psychological symptoms of dementia; systematic review; meta-analysis; animal-assisted intervention; pet-robot intervention

\section{Introduction}

In 2016, it was estimated that 47 million individuals are living with dementia worldwide, and this figure is projected to increase to 113 million in 30 years. As a result, the public health burden of dementia is anticipated to significantly increase in the coming years [1]. Currently, the World Health Organization is striving to promote dementia prevention and increase dementia awareness by significantly investing in health and welfare and active research into dementia [2]. Furthermore, many countries have 
implemented national strategies aimed at optimizing dementia management in preparation for the anticipated burden of dementia and its effects on their healthcare system [3]. Dementia patients commonly suffer from behavioral and psychological symptoms of dementia (BPSD) [4]. BPSD include socially inappropriate neurobehavioral symptoms such as mental and emotional symptoms, hyperactivity, and sleep disorders [5]. Depression and agitation are the most common emotional problems that affect dementia patients [4]. The goal of dementia treatment is to manage patients' inappropriate behaviors and psychological symptoms while considering their quality of life (QOL), and active research into cognitive stimulation therapy, a nonpharmacological intervention for dementia, is ongoing [6]. However, previous studies into therapies for dementia have generally focused on their effect on cognitive abilities such as memory, problem-solving ability, and communication skills, and the impact of these therapies on the psychological and social aspects of dementia has been neglected [7]. Recently, many interventions for the treatment of BPSD have received attention [8-10], including animal-assisted interventions [11,12].

Animal-assisted interventions (AAI) are interventions that involve animals. There are various subgroups of AAI, namely animal-assisted activities (AAA), animal-assisted therapies (AAT), and service animal programs (SAP) [13]. These are known to be effective interventions for older people with cognitive impairment, and recent studies have reported that AAI have positive effects on dementia patients [14]. AAA refer to unofficial activities involving animals that meet certain requirements and are characterized by a certain level of flexibility and spontaneity. AAT refer to interventions involving animals that are aimed at improving certain patient outcomes and are incorporated into rehabilitation programs [15]. SAP refers to programs that utilize trained animals to help clients with physical disabilities to overcome functional difficulties in their activities of daily living [16]. These interventions provide joy to patients, increase their motivation, and allow them to rest [17], and patients are able to resolve their unmet physical and emotional needs by being involved in activities related to patients therapeutic goals [18]. In particular, walking a living animal is not only beneficial to dementia patients but also facilitates the rehabilitation of adults who have undergone surgery or have an illness by reacquainting them with ambulation and recovering ambulation speed [19-21]. The first AAI to be developed were found to reduce depression [22], and the ability of AAI to reduce depression and improve QOL in older people with dementia is currently being investigated [11,23-25]. Despite the known benefits of AAI, their use is restricted in some medical environments due to concerns about patients having a fear of animals, possible infection risk, and fright [26].

Recently, pet-robot intervention (PRI) has been proposed as an alternative to AAI. PARO, the most widely studied PRI, is a seal-shaped robot which responds to light, temperature, touch, and posture and monitors the client's emotional changes and health status using sensors [27]. PARO is reported to have various beneficial psychological and social effects such as promoting interaction, reducing stress, and alleviating depression. Furthermore, PRI has similar effects to AAI involving living animals; overcomes the limitations associated with living animals; and has cost, hygiene, and safety benefits [28]. Notably, one study reported that PARO has a positive impact on depression and psychological agitation in older people with dementia and concluded that PARO is a nonpharmacological intervention effective at alleviating neuropsychiatric symptoms [29]. Furthermore, PARO alleviated stress and agitation and reduced the use of antipsychotics and analgesics in older people with dementia [30].

It is well-known that AAI and PRI have beneficial effects on symptoms of dementia [23,30]. In addition, systematic reviews of the effect of AAI or PRI on symptoms of dementia have been performed [31-33]. However, no studies have been conducted into the effects of both AAI and PRI on BPSD. Therefore, the aim of this systemic review and meta-analysis was to investigate the effects of AAI and PRI on BPSD and to present clinical evidence for the application of these interventions. 


\section{Results}

\subsection{Characteristics of the Included Studies}

Nine studies met the inclusion criteria for this study, and their general characteristics are presented in Table 1. Only studies with a PEDro score of 4-7 and thus deemed to be of "fair" or "good" quality were included [34]. A total of 507 participants were included in the meta-analysis. In the included studies, dementia patients were subjected to various interventions involving living or robotic animals. Each study was systematically analyzed and compared with the rest of the studies. The control group was typically subjected to the conventional treatment program provided at the hospital or facility at which the study was conducted. 
Table 1. Characteristics of the included studies.

\begin{tabular}{|c|c|c|c|c|c|c|c|c|c|}
\hline & \multirow[b]{2}{*}{ Study } & \multicolumn{2}{|c|}{$\begin{array}{c}\text { Participants } \\
\text { (Experimental/Control) }\end{array}$} & \multicolumn{4}{|c|}{ Intervention } & \multirow[b]{2}{*}{$\begin{array}{l}\text { Outcome } \\
\text { Measures }\end{array}$} & \multirow[b]{2}{*}{ Pedro Score } \\
\hline & & Age & Sample Size & & Experimental Group & Control Group & $\begin{array}{l}\text { Period/Total } \\
\text { Number of } \\
\text { Sessions }\end{array}$ & & \\
\hline 1 & $\begin{array}{c}\text { Majic } \\
\text { (2013) [35] }\end{array}$ & $\begin{array}{l}81.33 \pm 10.20 \\
/ 82.07 \pm 8.65\end{array}$ & $27 / 27$ & AAI (Dog) & Dog-assisted intervention & $\begin{array}{l}\text { Same care and treatment as } \\
\text { before the study }\end{array}$ & $\begin{array}{l}10 \text { weeks } \\
/ 10 \text { sessions }\end{array}$ & $\begin{array}{l}\text { MMSE, } \\
\text { CMAI, } \\
\text { DMAS * }\end{array}$ & 4 \\
\hline 2 & $\begin{array}{l}\text { Friedmann } \\
\text { (2015) [23] }\end{array}$ & $\begin{array}{l}79.59 \pm 9.74 \\
/ 82.11 \pm 8.36\end{array}$ & $22 / 18$ & AAI (Dog) & Dog-assisted intervention & Social skills and fine motor skills & $\begin{array}{c}12 \text { weeks } \\
\text { /24 sessions }\end{array}$ & $\begin{array}{l}\text { AES, CSDD, } \\
\text { CMAI }\end{array}$ & 6 \\
\hline 3 & $\begin{array}{c}\text { Olsen } \\
\text { (2016a) [11] }\end{array}$ & 65 or older & $25 / 26$ & AAI (Dog) & $\begin{array}{l}\text { Petting the dog, feeding the } \\
\text { dog a treat, and throwing a toy } \\
\text { for the dog to fetch }\end{array}$ & $\begin{array}{l}\text { Music therapy, sensory garden, } \\
\text { singing, exercise, cooking, } \\
\text { and handicrafts }\end{array}$ & $\begin{array}{l}12 \text { weeks } \\
/ 24 \text { sessions }\end{array}$ & $\begin{array}{l}\text { BARS, } \\
\text { CSDD*, } \\
\text { QUALID }\end{array}$ & 6 \\
\hline 4 & $\begin{array}{c}\text { Olsen } \\
\text { (2016b) [24] }\end{array}$ & 65 or older & $22 / 26$ & AAI (Dog) & $\begin{array}{l}\text { Petting the dog, feeding the } \\
\text { dog a treat, and throwing a toy } \\
\text { for the dog to fetch }\end{array}$ & Usual treatment & $\begin{array}{l}12 \text { weeks } \\
/ 24 \text { sessions }\end{array}$ & $\begin{array}{c}\text { BBS, } \\
\text { QUALID }\end{array}$ & 5 \\
\hline 5 & $\begin{array}{l}\text { Joranson } \\
\text { (2015) [29] }\end{array}$ & $\begin{array}{l}83.9 \pm 7.2 \\
/ 84.1 \pm 6.7\end{array}$ & $27 / 26$ & PRI (PARO) & $\begin{array}{l}\text { Petting, talking to and about, } \\
\text { smiling to, and singing to the } \\
\text { robotic animal }\end{array}$ & Usual treatment & $\begin{array}{l}12 \text { weeks } \\
/ 24 \text { sessions }\end{array}$ & $\begin{array}{l}\text { BARS * } \\
\text { CSDD * }\end{array}$ & 6 \\
\hline 6 & $\begin{array}{l}\text { Joranson } \\
\text { (2016) [36] }\end{array}$ & $\begin{array}{l}83.9 \pm 7.2 \\
/ 84.1 \pm 6.7\end{array}$ & $27 / 26$ & PRI (PARO) & $\begin{array}{l}\text { Petting, talking to and about, } \\
\text { smiling to, and singing to the } \\
\text { robotic animal }\end{array}$ & Usual treatment & $\begin{array}{l}12 \text { weeks } \\
/ 24 \text { sessions }\end{array}$ & $\begin{array}{l}\text { CDR, } \\
\text { QUALID }\end{array}$ & 7 \\
\hline 7 & $\begin{array}{l}\text { Petersen } \\
(2016)[30]\end{array}$ & $\begin{array}{l}83.5 \pm 5.8 \\
/ 83.3 \pm 6.0\end{array}$ & $35 / 26$ & PRI (PARO) & $\begin{array}{l}\text { Interaction activity of } 6 \text { people } \\
\text { one group to PARO }\end{array}$ & $\begin{array}{l}\text { Music therapy, physical activity, } \\
\text { and mental stimulation }\end{array}$ & $\begin{array}{l}12 \text { weeks } \\
/ 36 \text { sessions }\end{array}$ & $\begin{array}{l}\text { RAID }{ }^{* *}, \\
\text { CSDD **, } \\
\text { GDS, pulse } \\
\text { oximetry }^{* *}, \\
\text { pulse rate }{ }^{* *}, \\
\text { GSR }\end{array}$ & 6 \\
\hline 8 & $\begin{array}{l}\text { Liang } \\
\text { (2017) [37] }\end{array}$ & $67-98$ & $13 / 11$ & PRI (PARO) & $\begin{array}{l}\text { Separate PAROs were provided } \\
\text { to each participant's } \\
\text { home environment }\end{array}$ & $\begin{array}{l}\text { Standard activities (quizzes, } \\
\text { exercise, bingo, music, } \\
\text { and word activities) }\end{array}$ & $\begin{array}{l}6 \text { weeks } \\
/ 12-18 \\
\text { sessions }\end{array}$ & $\begin{array}{l}\text { CMAI-SF, } \\
\text { cognitive } \\
\text { score, NPI-Q, } \\
\text { depressive } \\
\text { symptoms * }\end{array}$ & 6 \\
\hline 9 & $\begin{array}{c}\text { Moyle } \\
\text { (2018) [38] }\end{array}$ & $\begin{array}{l}84 \pm 8.8 \\
/ 86 \pm 7.6 \\
/ 85 \pm 6.9\end{array}$ & $67 / 55 / 53$ & PRI (PARO) & $\begin{array}{l}\text { Participants were left alone } \\
\text { with PARO for } 15 \mathrm{~min} \text { to } \\
\text { interact with it as they liked }\end{array}$ & $\begin{array}{l}\text { PARO with all } \\
\text { artificial } \\
\text { intelligence } \\
\text { disabled }\end{array}$ & $\begin{array}{l}10 \text { weeks } \\
/ 30 \text { sessions }\end{array}$ & Sense Wear * & 7 \\
\hline
\end{tabular}

AAI, animal-assisted intervention; AES, Apathy Evaluation Scale; BARS, Brief Agitation Rating Scale; BBS, Berg Balance Scale; CDR, Clinical Dementia Rating Scale; CMAI, Cohen-Mansfield Agitation Inventory; CMAI-SF, Cohen-Mansfield Agitation Inventory Short Form; CSDD, Cornell Scale for Depression in Dementia; DMAS, Dementia Mood Assessment Scale; GDS, Global Deterioration Scale; GSR, galvanic skin response; MMSE, mini mental state examination; PRI, pet-robot intervention; RAID, Rating for Anxiety in Dementia; QUALID, Quality of Life in Late-Stage Dementia Scale; NPI-Q, Neuropsychiatric Inventory Brief Questionnaire; * $p<0.05,{ }^{* *} p<0.01$. 


\subsection{Meta-Analysis of the Effects of AAI and PRI}

\subsubsection{Meta-Analysis of the Effects of AAI and PRI on Agitation in Dementia Patients}

In the meta-analysis of the effects of AAI and PRI on agitation in dementia patients, the effect size was $0.70\left(95 \%\right.$ confidence interval: $\left.p=0.12, \mathrm{I}^{2}=89 \%\right)$, which was considered a large effect size. Overall, AAI and PRI did not significantly affect agitation in dementia patients (Figure 1).

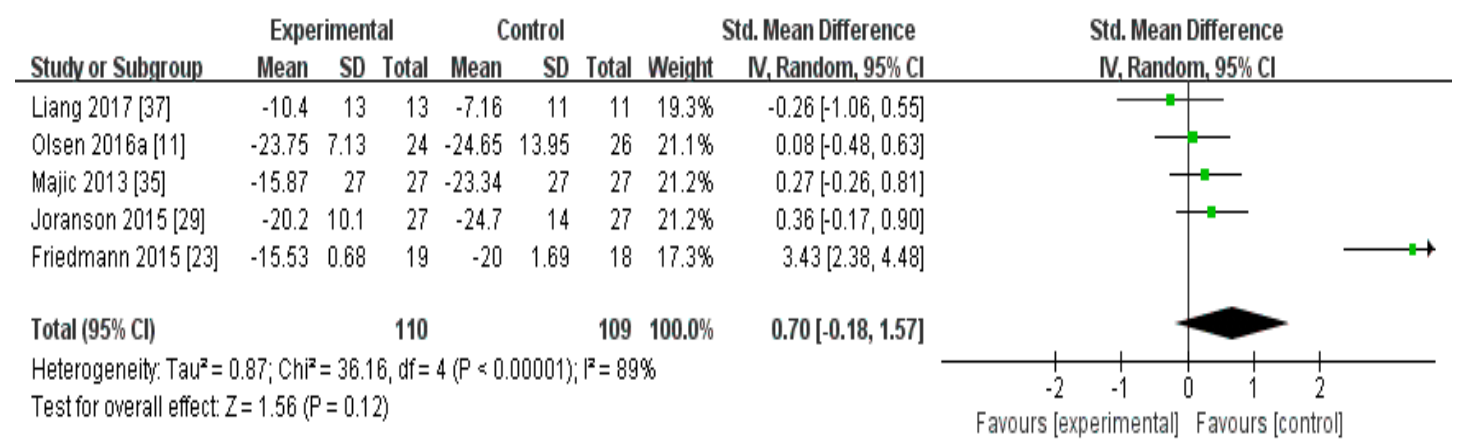

Figure 1. Forest plot of the effect of animal-assisted intervention and pet-robot intervention on agitation in dementia patients.

\subsubsection{Meta-Analysis of the Effects of AAI and PRI on Depression in Dementia Patients}

In the meta-analysis of the effects of AAI and PRI on depression in dementia patients, the effect size was -0.47 (95\% confidence interval: $p<0.001, \mathrm{I} 2=0 \%)$. Overall, AAI and PRI significantly reduced depression in dementia patients (Figure 2).

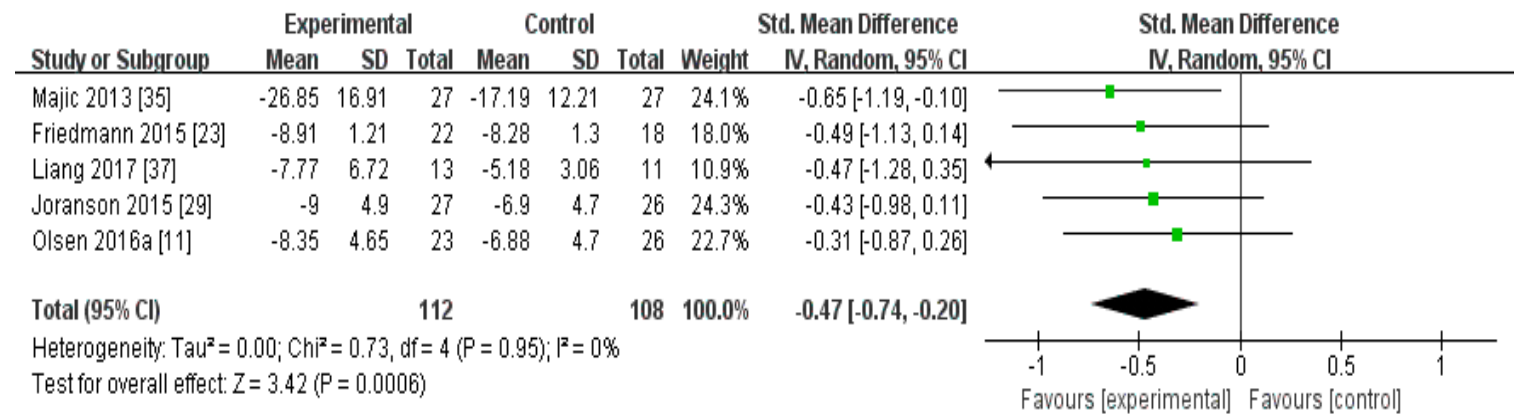

Figure 2. Forest plot of the effect of animal-assisted intervention and pet-robot intervention on depression in dementia patient.

\subsubsection{Meta-Analysis of the Effects of AAI and PRI on the QOL of Dementia Patients}

In the meta-analysis of the effects of AAI and PRI on the QOL of dementia patients, the effect size was 0.13 (95\% confidence interval: $p=0.34, \mathrm{I}^{2}=0 \%$, which was considered a small effect size. Overall, AAI and PRI did not significantly affect the QOL of dementia patients (Figure 3). 


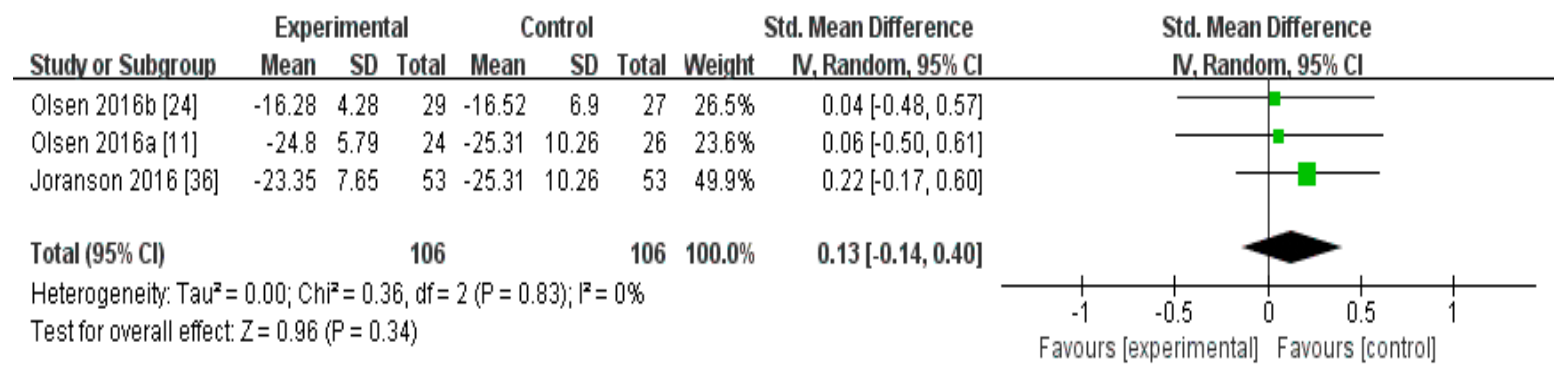

Figure 3. Forest plot of the effect of animal-assisted intervention and pet-robot intervention on the quality of life of dementia patients.

\subsubsection{Publication Bias}

When publication bias with respect to agitation, four studies were within the $95 \%$ confidence interval and were plotted to the left of the overall effect estimate (Figure 4A). When publication bias with respect to depression and QOL with respect to the effect of AAI and PRI was assessed (Figure 4B,C), all plotted dots were within the $95 \%$ confidence interval.

A

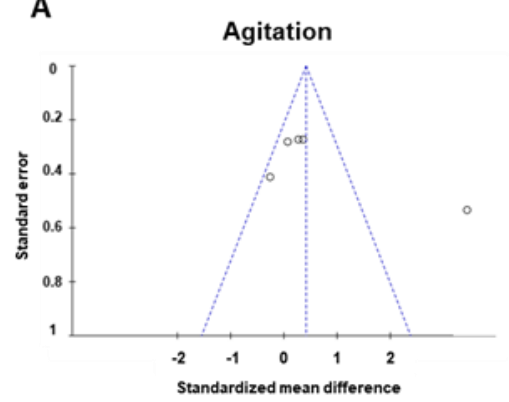

B

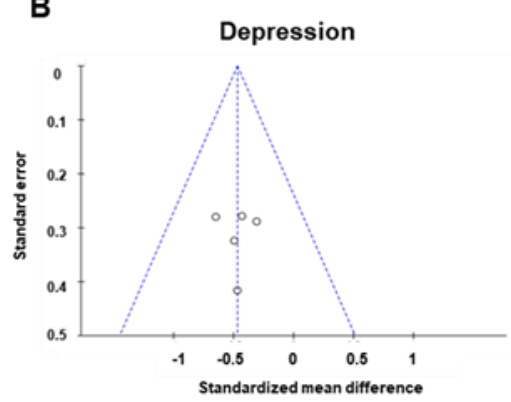

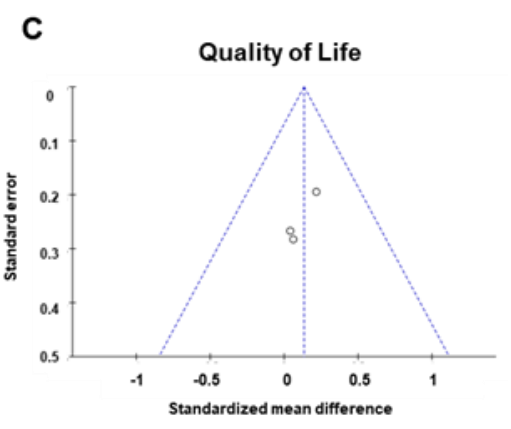

Figure 4. Funnel plots used to assess the existence of publication bias in the included studies. Publication bias of (A) agitation, (B) depression, and (C) quality of life.

\section{Discussion}

Currently, more than $90 \%$ of dementia patients suffer from BPSD [39], which poses major difficulties to both dementia patients and their caregivers. The type of BPSD varies according to dementia type, stage of the illness and various other factors. Particularly, patients of frontotemporal lobar degeneration (FTLD) show more prominent behavioral variants such as disinhibition, impulsivity, aggression, and personality change than those with other types of dementia [40-42]. Another study demonstrated that patients with dementia with Lewy bodies (DLB) present hallucinations and aberrant motor behavior (AMB) more so than Alzheimer's disease (AD) patients [43,44]. An increased rate of anxiety, depression, and psychosis may occur in vascular dementia (VD) $[40,43,45]$. Depression and agitation are the most common symptoms affecting various dementia patients. Furthermore, it is known that agitation, apathy, disinhibition, irritability, and motor dysfunction become serious as dementia progresses. In particular, depression and anxiety become more severe in the moderate stage of dementia [46-48]. In the early stages of dementia, apathy mainly appears, which is one of the first symptoms of the various forms of dementia. Apathy is a dangerous barrier that affects social interaction and activities of daily living due to lack of interest, enthusiasm, and apathetic response to interpersonal communication [49]. These psychological and behavioral changes from the early stages of dementia can affect aspects of BPSD such as depression and anxiety more seriously as dementia progress. Although BPSD, which varies depending on the type and progression of dementia, contains a range of important symptoms that affect the quality of life, stress, and prognosis of dementia patients and their caregivers, there is little of interest in and study on nonpharmacological interventions to treat BPSD. Thus, we performed a meta-analysis to investigate the effect of AAI and PRI-one of the 
nonpharmacological interventions using animals — on agitation, depression, and QOL in dementia patients $[15,26,27]$.

The meta-analysis of the effects of AAI and PRI on agitation showed a medium effect size of 0.70 (Figure 1). Three studies that utilized AAI and two studies that utilized PRI were included in the meta-analysis. The studies that used AAI reported larger effect sizes than those that used PRI, but AAI and PRI were not found to significantly affect agitation overall $[23,24,35]$. Our result contrasts with the results of a previous study which showed an alleviation in the agitation. However, since the level of evidence for the randomized controlled trials (RCTs) in previous studies was very low, we thought that the opposite results were obtained. Accordingly, our results support the suggestion of previous studies that the level of evidence is low [32].

The meta-analysis of the effects of AAI and PRI on depression showed a medium effect size of -0.47 (Figure 2). Three studies that used AAI were included, and two reported that this intervention strategy reduced depression $[23,24,35]$. Two studies that used PRI were included, and these showed a medium effect size $[36,37]$. AAI and PRI were found to significantly reduce depression, which serves as evidence that AAI and PRI are effective at reducing depression in dementia patients $(p<0.001)$.

The meta-analysis of the effects of AAI and PRI on QOL showed a small effect size of 0.13 , but the results were not statistically significant $(p>0.05)$ (Figure 3). Two studies used AAI, and both reported that these interventions improved QOL $[11,24]$. One study used PRI, and reported that this intervention did not significantly affect QOL [36]. The meta-analysis results showed that AAI and PRI did not significantly affect QOL, which supports previous findings [32].

The present study analyzed the effects of AAI and PRI on BPSD and found that these interventions did not affect agitation or QOL but significantly reduced depression. It is well known that the brain with depression in dementia has reduced connectivity on amygdala and emotion control regions [50,51]. AAI and PRI provide an emotional effect and a and sense of closeness to dementia patients [52], which may the reduced amygdala connectivity in dementia patients. In addition, AAI and PRI could have a positive effect on hippocampus in the brain with depression through activities that require memory, such as checking the health of animals, walking, and feeding. On the other hand, the agitation-related connectivity is the orbital frontal cortex and anterior cingulate cortex, which is a region that has little association with emotional support obtained through activities with animals. Thus, AAI and PRI did not show a significant effect in agitation. Although AAI and PRI have been effective in improving depression, it is difficult to dramatically relieve all BPSD symptoms. Moreover, it is known that BPSD is specifically related with the patient's low of QOL [53]. Therefore, in this study, it is considered that AAI and PRI were difficult to significantly influence QOL. A previous meta-analysis reported that AAI do not affect activities of daily living, depression, agitation, QOL, or cognitive function. In addition, a number of limitations are associated with interventions involving the use of living animals: patients may be fearful of or allergic to animals, animals may provoke falls in vulnerable patients, and animals may pose an infection risk to patients [32]. Moreover, there are a number of difficulties associated with managing animals-they need to be fed, produce feces, and may smell. However, it is clear that AAI can enhance the emotional wellbeing and QOL of dementia patients. Although robotic animals cannot evoke the same variety of emotions and sensations as living animals, they are easier to manage and could aid patients wherever needed. Subsequent studies should additionally examine the impact of living animals and robotic animals on the emotional wellbeing, cognitive function, and physical ability of dementia patients. Furthermore, patients should be followed-up to investigate the efficacy of these interventions in slowing the progression of dementia.

Several studies have suggested that psychiatric symptoms such as depression and anxiety are associated with dementia and cognitive impairment [54-56]. Indeed, patients with dementia have an increased risk of major depression, and many suffer from anxiety [57,58]. Interestingly, amyloid-beta $(\mathrm{A} \beta)$ burden and tau-related pathology are known to worsen in Alzheimer-type dementia with depression [55,59]. In addition, depression and agitation are causative factors of sleep disorders, and they can promote the development of dementia by inhibiting $\mathrm{A} \beta$ clearance and inducing systemic 
inflammation [60-63]. Therefore, it is important to alleviate the psychological symptoms of dementia patients. In this study, we confirmed that AAI and PRI can relieve the psychological symptoms of dementia patients. Several mechanisms by which AAI and PRI may affect BPSD have been proposed. First, AAI and PRI affect hormone levels. Previous studies consistently reported that dog-raising people exhibit higher levels of oxytocin, a hypothalamic neuropeptide $[64,65]$. Oxytocin is closely related to cognitive function, depression, agitation, and social communication and has been proposed as a pharmacological intervention for neurobehavioral disorders in patients with prefrontal dementia [66,67]. In addition, it has been reported that animal owners exhibit reduced cortisol levels [68]. In AD, cortisol levels substantially increase and this steroid hormone elicits neurotoxic effects in the hippocampus and thus exacerbates $A \beta$ pathology and contributes to cognitive impairment [69]. Therefore, AAI may improve BPSD by increasing oxytocin levels and reducing cortisol levels. Furthermore, the relationship between loneliness and depression is well established, and loneliness has been reported to promote $\mathrm{A} \beta$ deposition in the brain of $\mathrm{AD}$ patients [70,71]. In addition, loneliness is known to contribute to cognitive decline by lowering cognitive reserve [72]. Surprisingly, AAI is known to reduce the loneliness of residents in long-term care facilities [73]. Therefore, AAI and PRI may effectively reduce loneliness and depression in dementia patients.

Second, it is possible that AAI and PRI modulate brain structure and functional connectivity. Patients with dementia exhibit atrophy of the hippocampus and entorhinal cortex, areas of the brain associated with emotional and spatial memory [74]. In addition, late-stage dementia is associated with dysfunction of the amygdala and cerebral cortex [75,76]. Accordingly, patients with dementia have problems with language, reasoning, emotions, and social behavior. Furthermore, atrophy of the hippocampus and cerebral cortex affects the functional connectivity of frontotemporal and limbic circuits involved in depression and mood regulation [77]. Strikingly, emotion-related brain areas may be affected by dementia patients' relationship and emotional stability. Indeed, improvements in executive function, social skills, mood regulation, learning, memory, and attention were noted in patients receiving cognitive rehabilitation therapy through various AAI [52]. In addition, in children with ADHD, AAI had a calming effect, increased motivation, improved cognitive function, and promoted socialization [78]. It is thought that interaction with a therapy animal enhances functional connectivity between the frontotemporal and limbic systems. Moreover, having to look after an animal and remember to perform tasks such as feeding it is thought to improve memory and learning ability and attenuate hippocampal and cortical atrophy. Social interaction is possible through relationships and walking with animals, and through group meetings, depression will be alleviated. Although the neurological mechanisms underlying the effects of AAI and PRI have not been fully elucidated, accumulating evidence suggests that AAI and PRI can effectively improve BPSD.

Although a number of previous studies have also investigated living- and robotic- animal-assisted interventions for patients with dementia, our study has a number of strengths [31-33]. First, we comprehensively investigated the effects of interventions involving living and robotic animals and, for the first time, compared the effects of AAI and PRI on BPSD. Second, we demonstrated trends in research in this field and confirmed that more research is now being conducted into interventions involving robotic animals for dementia patients. Third, two reviewers independently identified articles that met the inclusion criteria, and a high level of inter-rater agreement was noted. Fourth, we focused on BPSD and dementia. Although AAI and PRI are known to affect various symptoms of dementia patients, we conducted a literature search and meta-analysis focusing on BPSD. Finally, it is difficult to distinguish between mild cognitive impairment (MCI) and dementia patients unless a neurological examination is performed to definitively diagnose dementia. In this study, we aimed to confirm the effect of AAI and PRI in individuals who had been diagnosed with dementia, not MCI.

Nevertheless, our study has a number of limitations. One limitation of the meta-analysis is the small number of included studies, which shows that there is a lack of literature relating to AAI and PRI for dementia patients. In addition, we only selected studies published in peer-reviewed journals and did not include any grey literature, which may have introduced publication bias. Third, we were 
unable to identify specific subgroups of dementia patients who may benefit most from AAI and PRI. Finally, we searched only a few English language databases, so some relevant studies may have been missed.

\section{Methods}

\subsection{Subsection}

A meta-analysis was performed to analyze and validate studies that investigated the effects of $\mathrm{AAI}$ and PRI on dementia patients.

\subsection{Search Strategy}

Studies into the effect of AAI and PRI on dementia patients published between January 2000 and August 2019 were analyzed. Data were collected from three electronic databases-the Cochrane Library, Embase, and PubMed (Figure 5). The search terms used were "Dementia" AND "animal-assisted therapy OR animal-assisted activity OR service animal programs OR animal OR robot". A total of 5364 studies were initially identified, and, after the exclusion of 4858 nonclinical trials, 506 studies underwent further analysis. An additional 506 studies were then excluded: 1 because the original text was unavailable, 9 because they were written in a language other than English, 173 because they were not RCTs, 216 because they were duplicates, 92 because they were inappropriate for the purpose of our study/because they were unsuitable based on a review of their titles and abstracts, and 7 because data were missing or disorganized. Ultimately, nine studies were included in the systematic review and meta-analysis. 


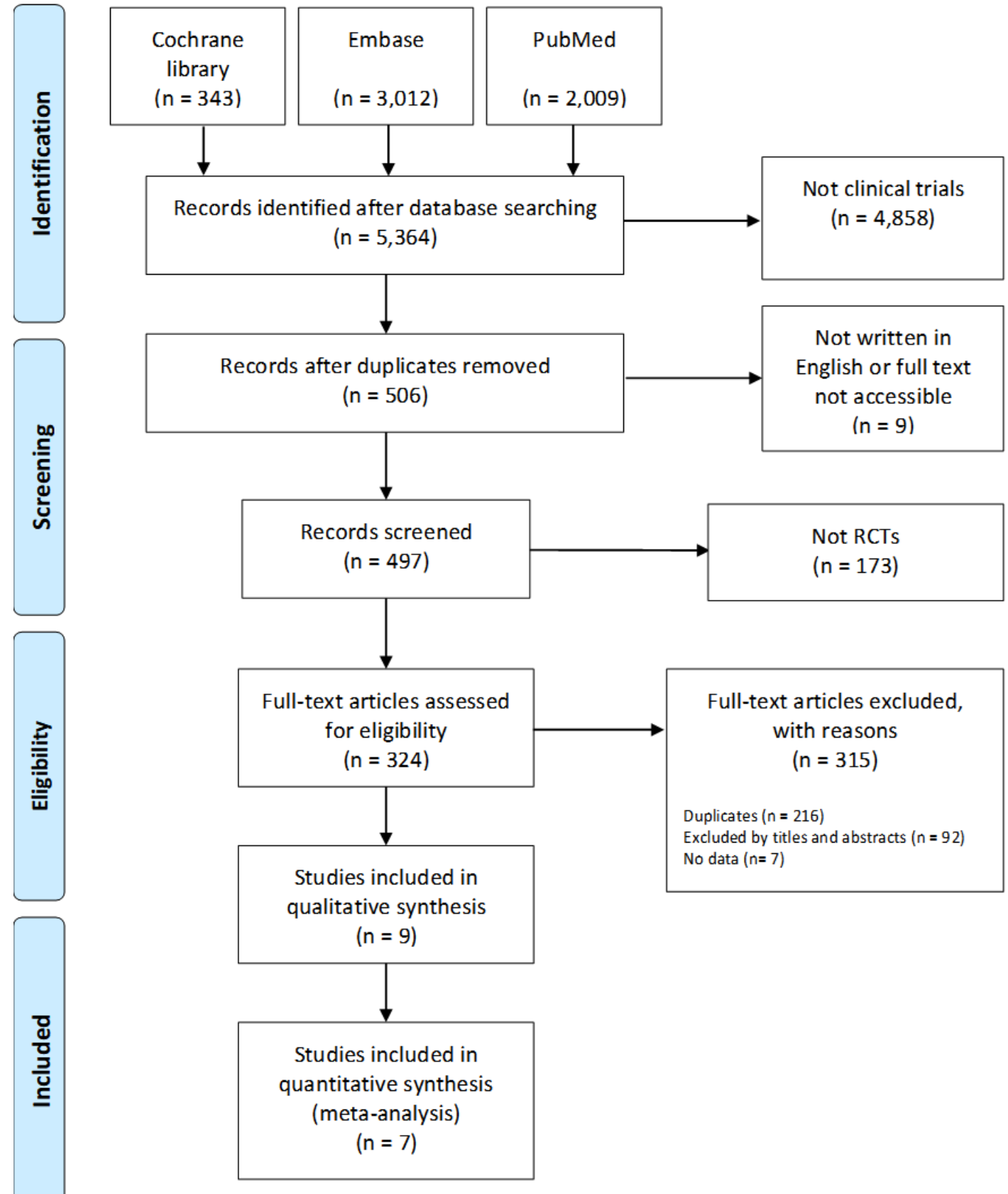

Figure 5. Flow chart of the systematic literature review.

\subsection{Selection Criteria}

Studies were included if they met all of the following criteria: (i) the study population comprised dementia patients, (ii) the experimental intervention was an AAI or PRI, (iii) the participants were randomized into groups, (iv) standardized evaluations were conducted to compare the effects of the intervention and control treatment, and (v) sufficient data were available to compute the effect size.

\subsection{Study Selection and Data Extraction}

Two reviewers (S.P. and A.B.) independently identified studies that met the inclusion criteria and performed data extraction. Disagreements between the reviewers were resolved by discussion. From each selected study, the following data were extracted: author, year of publication, mean age of 
the participants, study design (sample size, intervention type, follow-up duration, and frequency of intervention), and outcome measurement tools.

\subsection{Qualitative Assessment of Study Methodology}

One reviewer (S.P.) assessed the quality of the nine selected studies by assigning each a PEDro score (OTseeker, 2003), and the results were verified by the other reviewer (A.B.). The PEDro score ranges from 0-10 and the quality of a study is classified as "poor" ( $\leq 3)$, "fair" (4-5), "good" (6-8), or "excellent" (9-10) [34]. Studies deemed to be of "fair" to "good" quality (4-7) were included in this analysis. Any disagreements between the investigators with respect to the qualitative assessment of the studies were resolved by discussion.

\subsection{Qualitative Assessment of Study Methodology}

For each of the included studies, the following data were presented: name of first author/names of all authors, year of publication, age of participants, sample size, type of intervention/intervention method, duration and frequency of intervention, instruments used to assess primary outcomes, and PEDro score. To analyze the effects of AAI on dementia patients based on these characteristics, the mean, standard deviation, and sample size of the intervention and control groups were computed (Table 1). We examined whether the direction of the effect size was identical across studies and if not, made them equal by multiplying the mean by -1 [79].

\subsection{Statistical Analysis}

It is inappropriate to determine whether a fixed effect model or random effect model should be employed using the heterogeneity statistic $\mathrm{I}^{2}$. In order to select an appropriate effect model, the characteristics of the study, the subjects of the study, the method of intervention, and the mean value of the intervention effect were examined. In order to select an appropriate model to determine statistical heterogeneity, the characteristics of individual studies, study design, study subjects, intervention methods, and average values of intervention effects were examined [80].

Effect sizes were calculated to determine and compare the effect of AAI and PRI/different interventions on activities of daily living, stress, depression, and mental health using the sample size, mean, standard deviation, and statistically significant test of the experimental and control groups. According to the analysis criteria suggested by Cohen [81], 0.2 or less was considered a small effect size, 0.5 a medium effect size, and 0.8 or more a large effect size. The quantitative results of the meta-analysis were presented using forest plots. Publication bias was assessed by creating funnel plots. These were assessed by two reviewers and any disagreements were resolved by discussion. The chi-squared test was performed to determine the significance of the $Q$ statistic $[82,83]$. If the $p$-value of $Q$ was less than 0.10 , there was deemed to be significant statistical heterogeneity between studies. A higher significance level was used since the $Q$ statistic has low statistical power when only a small number of studies are included in a meta-analysis [84]. All statistical analyses were performed using Review Manager 5.3 software (RevMan; the Cochrane Collaboration, Oxford, UK).

\section{Conclusions}

This study systematically reviewed, compared, and meta-analyzed the impact of AAI and PRI on agitation, depression, and QOL in dementia patients. Interventions involving both living and robotic animals were investigated. The meta-analysis revealed that AAI and PRI interventions significantly reduced depression but did not affect agitation or QOL. Comparison of AAI and PRI showed that each method has its benefits and shortcomings and indicated that the two methods could potentially complement each other. Interventions involving living animals had a more beneficial effect on the emotional wellbeing of dementia patients than PRI. Although robotic animals overcome some limitations of living animals, they were not shown to alleviate BPSD in this study. In the future, more research should be conducted on the impact of living and robotic animals on the emotional 
wellbeing, cognitive function, and physical ability of dementia patients. Furthermore, we hope that AAI and PRI, which have been found to effectively reduce depression in dementia patients based on follow-ups, are more commonly utilized in clinical practice.

Author Contributions: Conceptualization, M.M. and D.-H.Y.; data curation, S.P. and A.B.; formal analysis, S.K. and Y.N.; funding acquisition, M.M. and D.-H.Y.; investigation, S.P. and A.B.; methodology S.P., A.B. and S.K.; project administration, M.M. and D.-H.Y.; resources, A.B. and S.K.; software, S.P. and D.-H.Y.; supervision, M.M. and D.-H.Y.; validation, S.K. and H.s.K.; visualization, S.K., Y.N. and H.s.K.; roles/writing-original draft, S.P., A.B., and S.K.; writing-review and editing, M.M. and D.-H.Y. All authors have read and agreed to the published version of the manuscript.

Funding: This work was supported by the Basic Science Research Program of the National Research Foundation of Korea (NRF), which is funded by the Ministry of Science, ICT \& Future Planning (NRF-2018R1D1A3B07041059 to M.M.; NRF-2019R1G1A1004010 to D.-H.Y.) and by the Cooperative Research Program for Agriculture Science and Technology Development (Project No. PJ01319901 and PJ01428603), Rural Development Administration, Republic of Korea.

Conflicts of Interest: The authors declare no conflicts of interest.

\section{Abbreviations}

$\begin{array}{ll}\text { AMB } & \text { aberrant motor behavior } \\ \text { AD } & \text { Alzheimer's disease } \\ \text { A } \beta & \text { amyloid- } \beta \\ \text { AAA } & \text { animal-assisted activities } \\ \text { AAI } & \text { Animal-assisted intervention } \\ \text { AAT } & \text { animal-assisted therapies } \\ \text { BPSD } & \text { behavioral and psychological symptoms of dementia } \\ \text { DLB } & \text { dementia with Lewy bodies } \\ \text { FTLD } & \text { frontotemporal lobar degeneration } \\ \text { MCI } & \text { mild cognitive impairment } \\ \text { PRI } & \text { pet-robot intervention } \\ \text { QOL } & \text { quality of life } \\ \text { RCTs } & \text { randomized controlled trials } \\ \text { RevMan } & \text { Review Manager } \\ \text { SAP } & \text { service animal programs } \\ \text { VD } & \text { vascular dementia }\end{array}$

\section{References}

1. Prince, M.; Comas-Herrera, A.; Knapp, M.; Guerchet, M.; Karagiannidou, M. World Alzheimer Report 2016: Improving Healthcare for People Living with Dementia: Coverage, Quality and Costs Now and in the Future; Alzheimer's Disease International: London, UK, 2016.

2. World Health Organization. Global Action Plan on the Public Health Response to Dementia; World Health Organization: Geneva, Switzerland, 2017.

3. Pimouguet, C.; Bassi, V.; Somme, D.; Lavallart, B.; Helmer, C.; Dartigues, J.F. The 2008-2012 French Alzheimer plan: A unique opportunity for improving integrated care for dementia. J. Alzheimers Dis. 2013, 34, 307-314. [CrossRef] [PubMed]

4. Kales, H.C.; Gitlin, L.N.; Lyketsos, C.G. Assessment and management of behavioral and psychological symptoms of dementia. BMJ 2015, 350, h369. [CrossRef] [PubMed]

5. Van der Linde, R.M.; Dening, T.; Matthews, F.E.; Brayne, C. Grouping of behavioural and psychological symptoms of dementia. Int. J. Geriatr. Psychiatry 2014, 29, 562-568. [CrossRef]

6. Cooper, C.; Mukadam, N.; Katona, C.; Lyketsos, C.G.; Ames, D.; Rabins, P.; Engedal, K.; de Mendonca Lima, C.; Blazer, D.; Teri, L.; et al. Systematic review of the effectiveness of non-pharmacological interventions to improve quality of life of people with dementia. Int. Psychogeriatr. 2012, 24, 856-870. [CrossRef] [PubMed]

7. Yuill, N.; Hollis, V. A systematic review of cognitive stimulation therapy for older adults with mild to moderate dementia: An occupational therapy perspective. Occup. Ther. Int. 2011, 18, 163-186. [CrossRef] 
8. Gill, S.S.; Bronskill, S.E.; Normand, S.L.; Anderson, G.M.; Sykora, K.; Lam, K.; Bell, C.M.; Lee, P.E.; Fischer, H.D.; Herrmann, N.; et al. Antipsychotic drug use and mortality in older adults with dementia. Ann. Intern. Med. 2007, 146, 775-786. [CrossRef]

9. Guetin, S.; Portet, F.; Picot, M.C.; Pommie, C.; Messaoudi, M.; Djabelkir, L.; Olsen, A.L.; Cano, M.M.; Lecourt, E.; Touchon, J. Effect of music therapy on anxiety and depression in patients with Alzheimer's type dementia: Randomised, controlled study. Dement. Geriatr. Cogn. Disord. 2009, 28, 36-46. [CrossRef]

10. Berkheimer, S.D.; Qian, C.; Malmstrom, T.K. Snoezelen Therapy as an Intervention to Reduce Agitation in Nursing Home Patients With Dementia: A Pilot Study. J. Am. Med. Dir. Assoc. 2017, 18, 1089-1091. [CrossRef]

11. Olsen, C.; Pedersen, I.; Bergland, A.; Enders-Slegers, M.J.; Patil, G.; Ihlebaek, C. Effect of animal-assisted interventions on depression, agitation and quality of life in nursing home residents suffering from cognitive impairment or dementia: A cluster randomized controlled trial. Int. J. Geriatr. Psychiatry 2016, 31, 1312-1321. [CrossRef]

12. Jones, C.; Moyle, W.; Murfield, J.; Draper, B.; Shum, D.; Beattie, E.; Thalib, L. Does Cognitive Impairment and Agitation in Dementia Influence Intervention Effectiveness? Findings From a Cluster-Randomized-Controlled Trial With the Therapeutic Robot, PARO. J. Am. Med. Dir. Assoc. 2018, 19, 623-626. [CrossRef]

13. Kruger, K.A.; Serpell, J.A. Animal-Assisted Interventions in Mental Health; Academic Press: Cambridge, MA, USA, 2010. [CrossRef]

14. Friedmann, E.; Galik, E.; Thomas, S.A.; Hall, S.; Cheon, J.; Han, N.; Kim, H.J.; McAtee, S.; Gee, N.R. Relationship of Behavioral Interactions during an Animal-assisted Intervention in Assisted Living to Health-related Outcomes. Anthrozoös 2019, 32, 221-238. [CrossRef]

15. Kamioka, H.; Okada, S.; Tsutani, K.; Park, H.; Okuizumi, H.; Handa, S.; Oshio, T.; Park, S.J.; Kitayuguchi, J.; Abe, T.; et al. Effectiveness of animal-assisted therapy: A systematic review of randomized controlled trials. Complement. Ther. Med. 2014, 22, 371-390. [CrossRef] [PubMed]

16. American Veterinary Medical Association. Guidelines for Animal Assisted Activity, Animal-Assisted Therapy and Resident Animal Programs; Current as of 2007; American Veterinary Medical Association: Schaumburg, IL, USA, 2014.

17. Ohtani, N.; Narita, S.; Yoshihara, E.; Ohta, M.; Iwahashi, K. Psychological Evaluation of Animal-assisted Intervention (AAI) Programs Involving Visiting Dogs and Cats for Alcohol Dependents: A Pilot Study. Nihon Arukoru Yakubutsu Igakkai Zasshi 2015, 50, 289-295. [PubMed]

18. Ebener, J.; Oh, H. A Review of Animal-Assisted Interventions in Long-Term Care Facilities. Act. Adapt. Aging 2017, 41, 107-128. [CrossRef]

19. Abate, S.V.; Zucconi, M.; Boxer, B.A. Impact of canine-assisted ambulation on hospitalized chronic heart failure patients' ambulation outcomes and satisfaction: A pilot study. J. Cardiovasc. Nurs. 2011, 26, 224-230. [CrossRef]

20. Ruzic, A.; Miletic, B.; Ruzic, T.; Persic, V.; Laskarin, G. Regular dog-walking improves physical capacity in elderly patients after myocardial infarction. Coll. Antropol. 2011, 35 (Suppl. 2), 73-75.

21. Rondeau, L.; Corriveau, H.; Bier, N.; Camden, C.; Champagne, N.; Dion, C. Effectiveness of a rehabilitation dog in fostering gait retraining for adults with a recent stroke: A multiple single-case study. NeuroRehabilitation 2010, 27, 155-163. [CrossRef]

22. Souter, M.A.; Miller, M.D. Do Animal-Assisted Activities Effectively Treat Depression? A Meta-Analysis. Anthrozoös 2015, 20, 167-180. [CrossRef]

23. Friedmann, E.; Galik, E.; Thomas, S.A.; Hall, P.S.; Chung, S.Y.; McCune, S. Evaluation of a pet-assisted living intervention for improving functional status in assisted living residents with mild to moderate cognitive impairment: A pilot study. Am. J. Alzheimers Dis. Other Demen. 2015, 30, 276-289. [CrossRef]

24. Olsen, C.; Pedersen, I.; Bergland, A.; Enders-Slegers, M.J.; Ihlebaek, C. Effect of animal-assisted activity on balance and quality of life in home-dwelling persons with dementia. Geriatr. Nurs. 2016, 37, $284-291$. [CrossRef]

25. Travers, C.; Perkins, J.; Rand, J.; Bartlett, H.; Morton, J. An evaluation of dog-assisted therapy for residents of aged care facilities with dementia. Anthrozoös 2013, 26, 213-225. [CrossRef]

26. Velde, B.; Cipriani, J.; Fisher, G. Resident and therapist views of animal-assisted therapy: Implications for occupational therapy practice. Aust. Occup. Ther. J. 2005, 52, 43-50. [CrossRef] 
27. Bemelmans, R.; Gelderblom, G.J.; Jonker, P.; de Witte, L. Socially assistive robots in elderly care: A systematic review into effects and effectiveness. J. Am. Med. Dir. Assoc. 2012, 13, 114-120. [CrossRef] [PubMed]

28. Preuss, D.; Legal, F. Living with the animals: Animal or robotic companions for the elderly in smart homes? J. Med. Ethics 2017, 43, 407-410. [CrossRef]

29. Joranson, N.; Pedersen, I.; Rokstad, A.M.; Ihlebaek, C. Effects on symptoms of agitation and depression in persons with dementia participating in robot-assisted activity: A cluster-randomized controlled trial. J. Am. Med. Dir. Assoc. 2015, 16, 867-873. [CrossRef]

30. Petersen, S.; Houston, S.; Qin, H.; Tague, C.; Studley, J. The utilization of robotic pets in dementia care. J. Alzheimers Dis. 2017, 55, 569-574. [CrossRef]

31. Hu, M.; Zhang, P.; Leng, M.; Li, C.; Chen, L. Animal-assisted intervention for individuals with cognitive impairment: A meta-analysis of randomized controlled trials and quasi-randomized controlled trials. Psychiatry Res. 2018, 260, 418-427. [CrossRef]

32. Zafra-Tanaka, J.H.; Pacheco-Barrios, K.; Tellez, W.A.; Taype-Rondan, A. Effects of dog-assisted therapy in adults with dementia: A systematic review and meta-analysis. BMC Psychiatry 2019, 19, 41. [CrossRef]

33. Leng, M.; Liu, P.; Zhang, P.; Hu, M.; Zhou, H.; Li, G.; Yin, H.; Chen, L. Pet robot intervention for people with dementia: A systematic review and meta-analysis of randomized controlled trials. Psychiatry Res. 2019, 271, 516-525. [CrossRef]

34. Moseley, A.M.; Herbert, R.D.; Sherrington, C.; Maher, C.G. Evidence for physiotherapy practice: A survey of the Physiotherapy Evidence Database (PEDro). Aust. J. Physiother. 2002, 48, 43-49. [CrossRef]

35. Majic, T.; Gutzmann, H.; Heinz, A.; Lang, U.E.; Rapp, M.A. Animal-assisted therapy and agitation and depression in nursing home residents with dementia: A matched case-control trial. Am. J. Geriatr. Psychiatry 2013, 21, 1052-1059. [CrossRef] [PubMed]

36. Joranson, N.; Pedersen, I.; Rokstad, A.M.; Ihlebaek, C. Change in quality of life in older people with dementia participating in Paro-activity: A cluster-randomized controlled trial. J. Adv. Nurs. 2016, 72, 3020-3033. [CrossRef] [PubMed]

37. Liang, A.; Piroth, I.; Robinson, H.; MacDonald, B.; Fisher, M.; Nater, U.M.; Skoluda, N.; Broadbent, E. A pilot randomized trial of a companion robot for people with dementia living in the community. J. Am. Med. Dir. Assoc. 2017, 18, 871-878. [CrossRef] [PubMed]

38. Moyle, W.; Jones, C.; Murfield, J.; Thalib, L.; Beattie, E.; Shum, D.; O’Dwyer, S.; Mervin, M.C.; Draper, B. Effect of a robotic seal on the motor activity and sleep patterns of older people with dementia, as measured by wearable technology: A cluster-randomised controlled trial. Maturitas 2018, 110, 10-17. [CrossRef]

39. Colombo, M.; Vitali, S.; Cairati, M.; Vaccaro, R.; Andreoni, G.; Guaita, A. Behavioral and psychotic symptoms of dementia (BPSD) improvements in a special care unit: A factor analysis. Arch. Gerontol. Geriatr. 2007, 44 (Suppl. 1), 113-120. [CrossRef]

40. Srikanth, S.; Nagaraja, A.V.; Ratnavalli, E. Neuropsychiatric symptoms in dementia-frequency, relationship to dementia severity and comparison in Alzheimer's disease, vascular dementia and frontotemporal dementia. J. Neurol. Sci. 2005, 236, 43-48. [CrossRef]

41. Levy, M.L.; Miller, B.L.; Cummings, J.L.; Fairbanks, L.A.; Craig, A. Alzheimer disease and frontotemporal dementias. Behavioral distinctions. Arch. Neurol. 1996, 53, 687-690. [CrossRef]

42. Warren, J.D.; Rohrer, J.D.; Rossor, M.N. Clinical review. Frontotemporal dementia. BMJ 2013, 347 , f4827. [CrossRef]

43. Kazui, H.; Yoshiyama, K.; Kanemoto, H.; Suzuki, Y.; Sato, S.; Hashimoto, M.; Ikeda, M.; Tanaka, H.; Hatada, Y.; Matsushita, M.; et al. Differences of behavioral and psychological symptoms of dementia in disease severity in four major dementias. PLoS ONE 2016, 11, e0161092. [CrossRef]

44. McKeith, I.G.; Boeve, B.F.; Dickson, D.W.; Halliday, G.; Taylor, J.P.; Weintraub, D.; Aarsland, D.; Galvin, J.; Attems, J.; Ballard, C.G.; et al. Diagnosis and management of dementia with Lewy bodies: Fourth consensus report of the DLB Consortium. Neurology 2017, 89, 88-100. [CrossRef]

45. Ballard, C.; Neill, D.; O’Brien, J.; McKeith, I.G.; Ince, P.; Perry, R. Anxiety, depression and psychosis in vascular dementia: Prevalence and associations. J. Affect. Disord. 2000, 59, 97-106. [CrossRef]

46. Zamboni, G.; Huey, E.D.; Krueger, F.; Nichelli, P.F.; Grafman, J. Apathy and disinhibition in frontotemporal dementia: Insights into their neural correlates. Neurology 2008, 71, 736-742. [CrossRef] [PubMed] 
47. Starkstein, S.E.; Migliorelli, R.; Manes, F.; Teson, A.; Petracca, G.; Chemerinski, E.; Sabe, L.; Leiguarda, R. The prevalence and clinical correlates of apathy and irritability in Alzheimer's disease. Eur. J. Neurol. 1995, 2, 540-546. [CrossRef] [PubMed]

48. Tanaka, H.; Hashimoto, M.; Fukuhara, R.; Ishikawa, T.; Yatabe, Y.; Kaneda, K.; Yuuki, S.; Honda, K.; Matsuzaki, S.; Tsuyuguchi, A.; et al. Relationship between dementia severity and behavioural and psychological symptoms in early-onset Alzheimer's disease. Psychogeriatrics 2015, 15, 242-247. [CrossRef]

49. Nobis, L.; Husain, M. Apathy in Alzheimer's disease. Curr. Opin. Behav. Sci. 2018, 22, 7-13. [CrossRef]

50. Yue, Y.; Yuan, Y.; Hou, Z.; Jiang, W.; Bai, F.; Zhang, Z. Abnormal functional connectivity of amygdala in late-onset depression was associated with cognitive deficits. PLoS ONE 2013, 8, e75058. [CrossRef]

51. Guo, Z.; Liu, X.; Hou, H.; Wei, F.; Liu, J.; Chen, X. Abnormal degree centrality in Alzheimer's disease patients with depression: A resting-state functional magnetic resonance imaging study. Exp. Gerontol. 2016, 79, 61-66. [CrossRef]

52. Stapleton, M. Effectiveness of animal assisted therapy after brain injury: A bridge to improved outcomes in CRT. NeuroRehabilitation 2016, 39, 135-140. [CrossRef]

53. Hurt, C.; Bhattacharyya, S.; Burns, A.; Camus, V.; Liperoti, R.; Marriott, A.; Nobili, F.; Robert, P.; Tsolaki, M.; Vellas, B.; et al. Patient and caregiver perspectives of quality of life in dementia. An investigation of the relationship to behavioural and psychological symptoms in dementia. Dement. Geriatr. Cogn. Disord. 2008, 26, 138-146. [CrossRef]

54. Ownby, R.L.; Crocco, E.; Acevedo, A.; John, V.; Loewenstein, D. Depression and risk for Alzheimer disease: Systematic review, meta-analysis, and metaregression analysis. Arch. Gen. Psychiatry 2006, 63, 530-538. [CrossRef]

55. Rapp, M.A.; Schnaider-Beeri, M.; Grossman, H.T.; Sano, M.; Perl, D.P.; Purohit, D.P.; Gorman, J.M.; Haroutunian, V. Increased hippocampal plaques and tangles in patients with Alzheimer disease with a lifetime history of major depression. Arch. Gen. Psychiatry 2006, 63, 161-167. [CrossRef] [PubMed]

56. Palmer, K.; Berger, A.K.; Monastero, R.; Winblad, B.; Backman, L.; Fratiglioni, L. Predictors of progression from mild cognitive impairment to Alzheimer disease. Neurology 2007, 68, 1596-1602. [CrossRef] [PubMed]

57. Kitching, D. Depression in dementia. Aust. Prescr. 2015, 38, 209-211. [CrossRef] [PubMed]

58. Kwak, Y.T.; Yang, Y.; Koo, M.S. Anxiety in dementia. Dement. Neurocogn. Disord. 2017, 16, 33-39. [CrossRef]

59. Rapp, M.A.; Schnaider-Beeri, M.; Purohit, D.P.; Perl, D.P.; Haroutunian, V.; Sano, M. Increased neurofibrillary tangles in patients with Alzheimer disease with comorbid depression. Am. J. Geriatr. Psychiatry 2008, 16, 168-174. [CrossRef]

60. Ooms, S.; Ju, Y.E. Treatment of sleep disorders in dementia. Curr. Treat. Options Neurol. 2016, 18, 40. [CrossRef]

61. Shokri-Kojori, E.; Wang, G.J.; Wiers, C.E.; Demiral, S.B.; Guo, M.; Kim, S.W.; Lindgren, E.; Ramirez, V.; Zehra, A.; Freeman, C.; et al. beta-Amyloid accumulation in the human brain after one night of sleep deprivation. Proc. Natl. Acad. Sci. USA 2018, 115, 4483-4488. [CrossRef]

62. Cordone, S.; Annarumma, L.; Rossini, P.M.; De Gennaro, L. Sleep and beta-Amyloid deposition in Alzheimer disease: Insights on mechanisms and possible innovative treatments. Front. Pharmacol. 2019, 10, 695. [CrossRef]

63. Irwin, M.R.; Vitiello, M.V. Implications of sleep disturbance and inflammation for Alzheimer's disease dementia. Lancet Neurol. 2019, 18, 296-306. [CrossRef]

64. Petersson, M.; Uvnas-Moberg, K.; Nilsson, A.; Gustafson, L.L.; Hydbring-Sandberg, E.; Handlin, L. Oxytocin and cortisol levels in dog owners and their dogs are associated with behavioral patterns: An exploratory study. Front. Psychol. 2017, 8, 1796. [CrossRef] [PubMed]

65. Nagasawa, M.; Kikusui, T.; Onaka, T.; Ohta, M. Dog's gaze at its owner increases owner's urinary oxytocin during social interaction. Horm. Behav. 2009, 55, 434-441. [CrossRef] [PubMed]

66. Jesso, S.; Morlog, D.; Ross, S.; Pell, M.D.; Pasternak, S.H.; Mitchell, D.G.; Kertesz, A.; Finger, E.C. The effects of oxytocin on social cognition and behaviour in frontotemporal dementia. Brain 2011, 134, 2493-2501. [CrossRef]

67. McQuaid, R.J.; McInnis, O.A.; Abizaid, A.; Anisman, H. Making room for oxytocin in understanding depression. Neurosci. Biobehav. Rev. 2014, 45, 305-322. [CrossRef] 
68. Handlin, L.; Hydbring-Sandberg, E.; Nilsson, A.; Ejdebäck, M.; Jansson, A.; Uvnäs-Moberg, K. Short-term interaction between dogs and their owners: effects on oxytocin, cortisol, insulin and heart rate-An exploratory study. Anthrozoös 2011, 24, 301-315. [CrossRef]

69. Ouanes, S.; Popp, J. High cortisol and the risk of dementia and Alzheimer's Disease: A review of the literature. Front. Aging Neurosci. 2019, 11, 43. [CrossRef] [PubMed]

70. Cacioppo, J.T.; Hawkley, L.C.; Thisted, R.A. Perceived social isolation makes me sad: 5-year cross-lagged analyses of loneliness and depressive symptomatology in the Chicago Health, Aging, and Social Relations Study. Psychol. Aging 2010, 25, 453-463. [CrossRef]

71. Donovan, N.J.; Okereke, O.I.; Vannini, P.; Amariglio, R.E.; Rentz, D.M.; Marshall, G.A.; Johnson, K.A.; Sperling, R.A. Association of higher cortical amyloid burden with loneliness in cognitively normal older adults. JAMA Psychiatry 2016, 73, 1230-1237. [CrossRef]

72. Scarmeas, N.; Stern, Y. Cognitive reserve and lifestyle. J. Clin. Exp. Neuropsychol. 2003, 25, 625-633. [CrossRef]

73. Banks, M.R.; Banks, W.A. The effects of animal-assisted therapy on loneliness in an elderly population in long-term care facilities. J. Gerontol. A Biol. Sci. Med. Sci. 2002, 57, M428-M432. [CrossRef]

74. Devanand, D.P.; Pradhaban, G.; Liu, X.; Khandji, A.; De Santi, S.; Segal, S.; Rusinek, H.; Pelton, G.H.; Honig, L.S.; Mayeux, R.; et al. Hippocampal and entorhinal atrophy in mild cognitive impairment: Prediction of Alzheimer disease. Neurology 2007, 68, 828-836. [CrossRef]

75. Cuenod, C.A.; Denys, A.; Michot, J.L.; Jehenson, P.; Forette, F.; Kaplan, D.; Syrota, A.; Boller, F. Amygdala atrophy in Alzheimer's disease. An in vivo magnetic resonance imaging study. Arch. Neurol. 1993, 50, 941-945. [CrossRef] [PubMed]

76. De la Monte, S.M. Quantitation of cerebral atrophy in preclinical and end-stage Alzheimer's disease. Ann. Neurol. 1989, 25, 450-459. [CrossRef] [PubMed]

77. Campbell, S.; Macqueen, G. The role of the hippocampus in the pathophysiology of major depression. J. Psychiatry Neurosci. 2004, 29, 417-426. [PubMed]

78. Busch, C.; Tucha, L.; Talarovicova, A.; Fuermaier, A.B.M.; Lewis-Evans, B.; Tucha, O. Animal-assisted interventions for children with attention deficit/hyperactivity disorder: A theoretical review and consideration of future research directions. Psychol. Rep. 2016, 118, 292-331. [CrossRef] [PubMed]

79. Kim, S.Y.; Park, J.E.; Seo, H.J.; Seo, H.S.; Son, H.J.; Sim, C.M.; Lee, Y.J.; Jang, B.H.; Heo, D.S. NECA's Guidance for Undertaking Systematic Reviews and Meta-Analyses for Intervention; National Evidence-Based Healthcare Collaborating Agency: Seoul, Korea, 2011; Volume 25.

80. Borenstein, M.; Hedges, L.V.; Higgins, J.P.; Rothstein, H.R. Overview. In Introduction to Meta-Analysis; John Wiley \& Sons: Hoboken, NJ, USA, 2009; Chapter 15; pp. 103-106. [CrossRef]

81. Cohen, J. Statistical Power Analysis for the Behavioral Sciences; L. Erlbaum Associates: Hillsdale, NJ, USA, 1988.

82. Cochran, W.G. Some Methods for Strengthening the Common $\chi^{2}$ Tests. Bioethics 1954. [CrossRef]

83. Furberg, C.D.; Morgan, T.M. Lessons from overviews of cardiovascular trials. Stat. Med. 1987, 6, $295-306$. [CrossRef]

84. Rosenthal, R.; Rubin, D.B. Comparing effect sizes of independent studies. Psychol. Bull. 1982, 92, 500-504. [CrossRef]

(C) 2020 by the authors. Licensee MDPI, Basel, Switzerland. This article is an open access article distributed under the terms and conditions of the Creative Commons Attribution (CC BY) license (http://creativecommons.org/licenses/by/4.0/). 